\title{
Effects of $\mathrm{MgSO}_{4}$ on neuromuscular blockade of rocuronium and sugammadex reversal in the isolated phrenic nerve-hemidiaphragm preparation of rats
}

\author{
Yang H.S. ${ }^{1}$, Cho C.-K. ${ }^{2}$, Sung T.-Y. ${ }^{2}$, Lee J.U. ${ }^{3}$
}

${ }^{1}$ Asan Medical Center, College of medicine, University of Ulsan, Dept of Anaesthesiology \& Pain Medicine, Seoul, Korea, Republic of, ${ }^{2}$ Konyang University Hospital, Konyang University College of Medicine, Dept of Anaesthesiology \& Pain Medicine, Daejeon, Korea, Republic of, ${ }^{3} \mathrm{Ch} u n g n a m$ National University School of Medicine, Dept of Anaesthesiology \& Pain Medicine, Daejeon, Korea, Republic of

\section{Background}

Perioperative magnesium sulphate( $\mathrm{MgSO} 4)$ use for analgesic, antiarrhythmic and obstetric purpose. The effects of increased $\mathrm{MgSO} 4$ in clinical practice on rocuronium induced neuromuscular block and sugammadex reversal is not clearly quantified. This studies were investigated the effect of $\mathrm{MgSO} 4$ on neuromuscular blockade of rocuronium and sugammadex reversal in the isolated phrenic nervehemidiaphragm preparation of rats.

\section{Materials and Methods}

Rat phrenic nerve-hemidiaphragm preparations were isolated and randomly allocated 4 groups by $\mathrm{MgSO}_{4}$ concentration [ $1 \mathrm{mM}, 2 \mathrm{mM}, 3 \mathrm{mM}, 4 \mathrm{mM}, \mathrm{N}=10$ in each group] in Krebs solution. TOFR and twitch height response were recorded mechanomyograhycally. The preparations were blocked by incremental dose of rocuronium(initial $200 \mu \mathrm{g}+$ booster $100 \mu \mathrm{g}$ in $75 \mathrm{ml}$ bath) and dose-response curve with $\mathrm{EC}_{5}, \mathrm{EC}_{50}, \mathrm{EC}_{90}$, $\mathrm{EC}_{95}$ of rocuronium in each group were calculated using a logistic model.For reversal, we used equimolar dose of sugammadex to administered rocuronium. Recovery index, time to maximal twitch height and TOFR $>0.9$ after sugammadex reversal was obtained.

\section{Results}

Table 1. Twitch height change after addition of $\mathrm{MgSO}_{4}$ to proper group

\begin{tabular}{lcccc}
\hline & $1 \mathrm{mM}$ & $2 \mathrm{mM}$ & $3 \mathrm{mM}$ & $4 \mathrm{mM}$ \\
\hline Stabilization $(1 \mathrm{mM})$ & $15.4 \pm 4.1$ & $13.1 \pm 2.2$ & $13.8 \pm 3.2$ & $14.0 \pm 3.7$ \\
MgSO4 added & $15.1 \pm 4.0$ & $12.2 \pm 2.0^{*}$ & $13.0 \pm 2.9^{*}$ & $12.5 \pm 3.3^{*}$ \\
Difference(\%) & $1.6 \pm 4.5$ & $6.5 \pm 4.7$ & $6.2 \pm 3.9$ & $10.6 \pm 3.9$ \\
\hline
\end{tabular}

* : $\mathrm{P}<0.05$ compared to $\mathrm{T} 1$ after stabilization
Table 2. $\mathrm{EC}_{5}, \mathrm{EC}_{50}, \mathrm{EC}_{90}, \mathrm{EC}_{95}$ of rocuronium

\begin{tabular}{lcccc}
\hline & $1 \mathrm{mM}$ & $2 \mathrm{mM}$ & $3 \mathrm{mM}$ & $4 \mathrm{mM}$ \\
\hline EC5 & $4.6 \pm 1.0$ & $3.4 \pm 1.0$ & $2.9 \pm 0.1$ & $3.0 \pm 0.4$ \\
EC50 & $8.4 \pm 1.1$ & $6.1 \pm 1.2^{*}$ & $4.7 \pm 0.4^{* \dagger}$ & $4.4 \pm 0.8^{* \dagger}$ \\
EC90 & $11.7 \pm 1.3$ & $8.7 \pm 1.4^{*}$ & $6.8 \pm 0.7^{* \dagger}$ & $6.4 \pm 0.9^{* \dagger}$ \\
EC95 & $12.5 \pm 1.4$ & $9.3 \pm 1.4^{*}$ & $7.4 \pm 0.9 * \dagger$ & $6.9 \pm 0.9^{* \dagger}$ \\
\hline
\end{tabular}

*: $\mathrm{P}<0.05$ compared to $1 \mathrm{mM}$ group

$\uparrow: \mathrm{p}<0.05$ compared to $2 \mathrm{mM}$ group

Fig 1. Dose response curve after rocuronium infusion

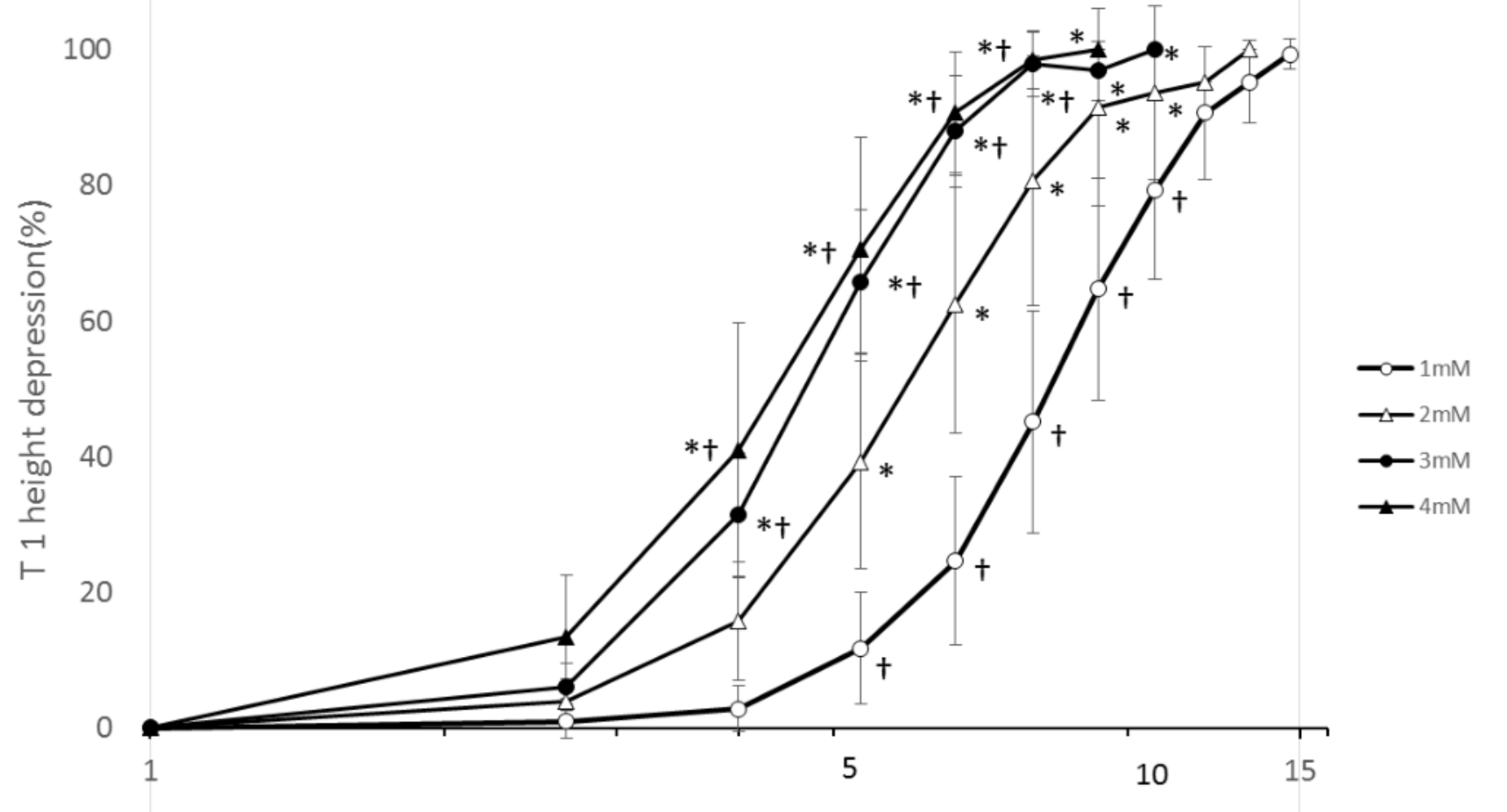

Concentration of rocuronium $(\mu \mathrm{g} / \mathrm{m} \ell)$

Fig 2. TOFR after sugammadex infusion (Mean \pm SD)

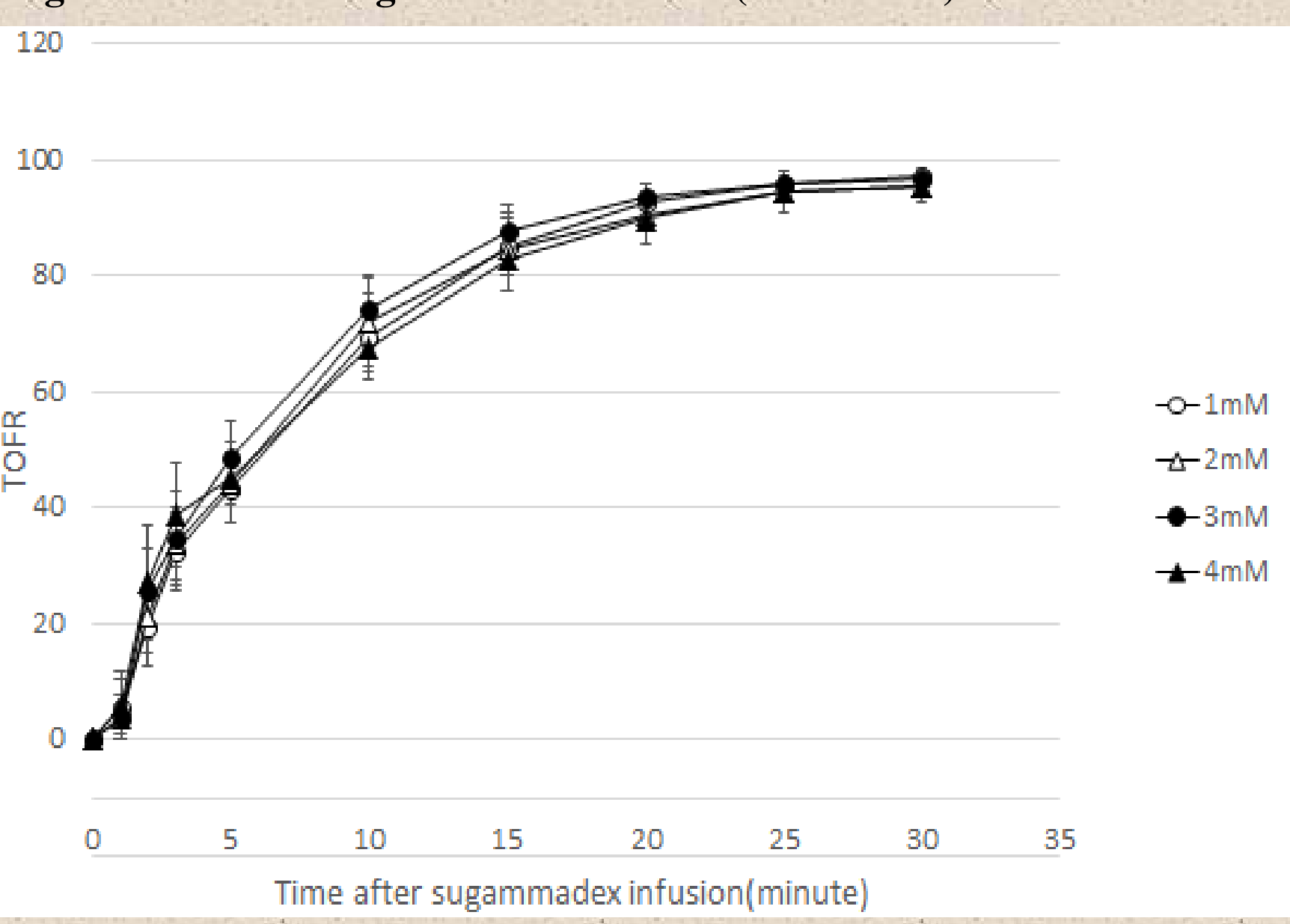

\section{Conclusion}

Increase of $\mathrm{MgSO}_{4}$ concentration ( $1 \mathrm{mM}$ to $3 \mathrm{mM}$ ) enhances rocuronium induced neuromuscular block in rats' hemidiaphragm preparations. Increase of $\mathrm{MgSO}_{4}$ concentration does not reduce reversal effect of equimolar dose of sugammadex to rocuronium in rats' hemidiaphragm preparation. 